\title{
PHOTOGRAMMETRY-DERIVED DIGITAL SURFACE MODEL AND ORTHOIMAGERY OF AREAS NEAR THE DALTON HIGHWAY, YUKON RIVER CROSSING, ALASKA
}

Gabriel J. Wolken and Katreen Wikstrom Jones

Raw Data File 2019-4

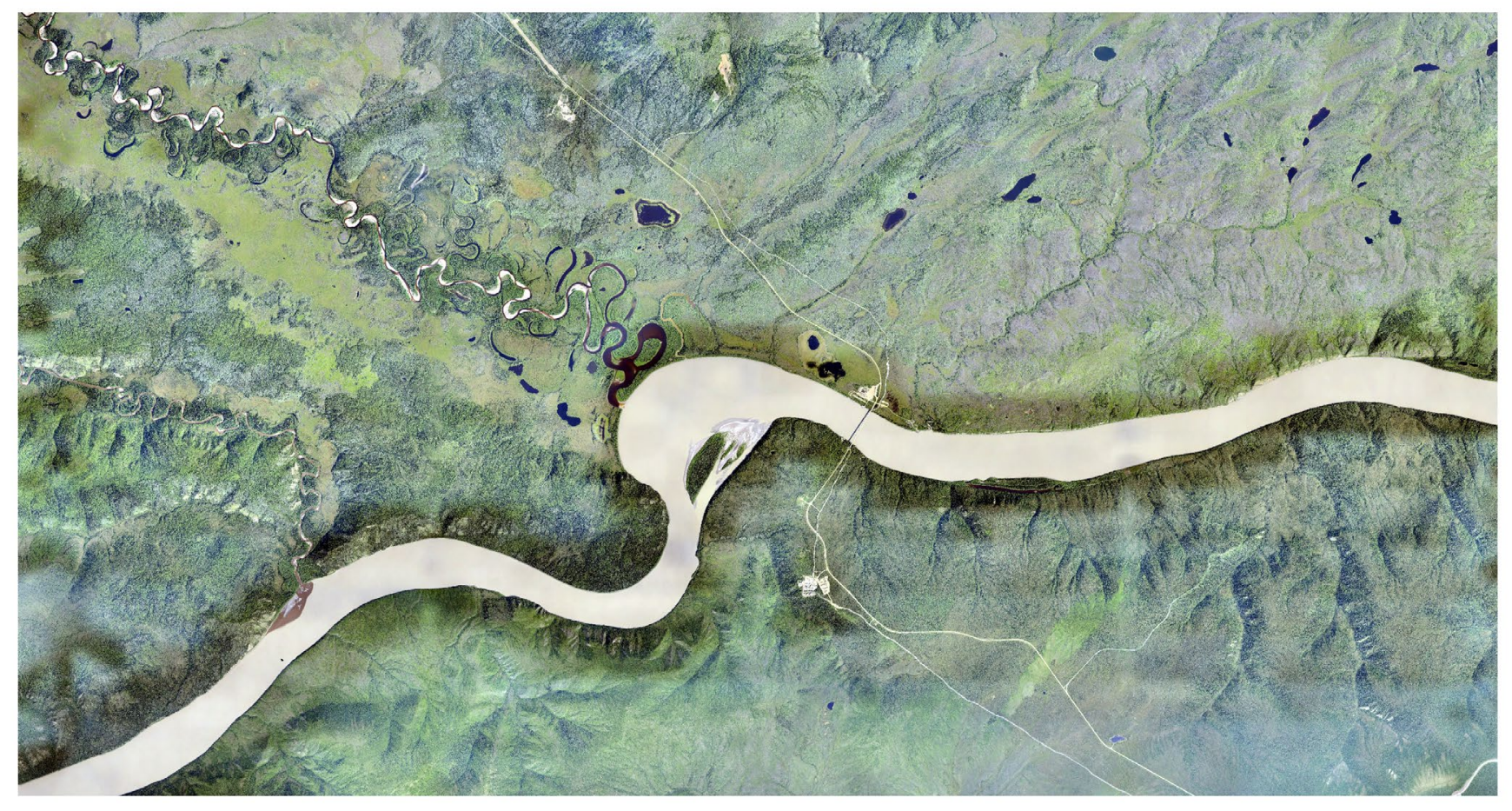

Orthoimagery of Yukon River Crossing acquired on June 30, 2016.

$\$ 1.00$

This report has not been reviewed for technical content or for conformity to the editorial standards of DGGS.

2019

STATE OF ALASKA

DEPARTMENT OF NATURAL RESOURCES

DIVISION OF GEOLOGICAL \& GEOPHYSICAL SURVEYS
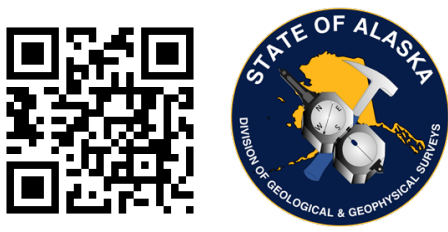


\section{PHOTOGRAMMETRY-DERIVED DIGITAL SURFACE MODEL AND ORTHOIMAGERY OF AREAS NEAR THE DALTON HIGHWAY YUKON RIVER CROSSING, ALASKA}

Gabriel J. Wolken ${ }^{1}$ and Katreen Wikstrom Jones ${ }^{1}$

\section{ABSTRACT}

The State of Alaska Division of Geological \& Geophysical Surveys (DGGS) produced a digital surface model (DSM) and an orthorectified aerial image (orthoimagery) over Yukon River Crossing in support of landslide hazard mapping (fig. 1). Aerial photographs and Global Navigation Satellite System (GNSS) data were collected on June 30, 2016, and were processed using Structure-from-Motion (SfM) photogrammetric techniques to create the DSM and orthoimagery. For the purpose of enabling open access to geospatial datasets in Alaska, this collection is being released as a Raw Data File with an open end-user license. All files can be downloaded free of charge from the DGGS website (doi.org/10.14509/30183).

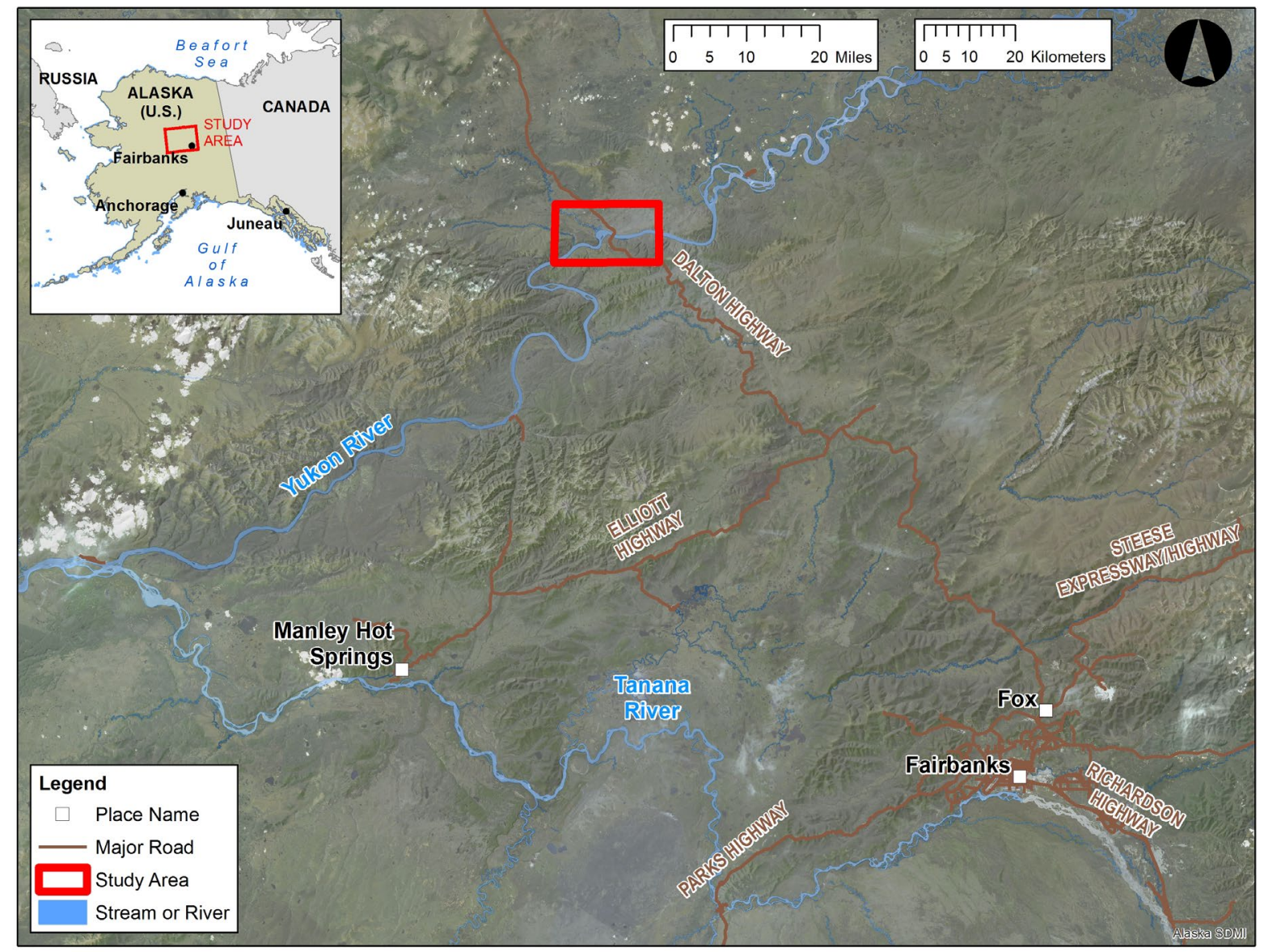

Figure 1. Map showing where the Dalton Highway crosses the Yukon River. Orthoimagery and DSMs were collected in the study area (red box). 


\section{DATA ACQUISITION}

DGGS collected digital aerial photographic data on June 30, 2016, using a fixed-wing (Cessna 180) airborne platform. The aerial photographic survey resulted in approximately 60 percent side lap and 80 percent end lap coverage, with an above ground-level flying height of 1,100-2,000 $\mathrm{m}$, which resulted in 4,922 photos with $0.24 \mathrm{~m}$ ground sample distance (GSD). The total area surveyed was approximately 360 $\mathrm{km}^{2}$.

A Nikon D800 with an AF-Nikkor 24mm f/5D lens was used to collect 36.2-megapixel JPEG photographs (7,360 x 4,912 pixels per image) which were compressed for optimal quality. The aerial photographic survey was controlled with an Aerometric flight control system and Aviatrix software that linked the camera shutter release with Global Navigation Satellite System (GNSS) event markers created by an onboard Trimble R7 receiver and a dual-band Novatel roof-mounted antenna mounted $0.96 \mathrm{~m}$ above the camera.

On September 21, 2016 checkpoints were collected as rapid-static occupations (15 min) with a Trimble R8 GNSS receiver. A Trimble R7 GNSS receiver with Zephyr-2 antenna was deployed near the center of the study area and was used as horizontal and vertical control for checkpoint baseline corrections.

\section{DATA PROCESSING}

\section{GNSS}

Aerial survey GNSS data (camera coordinates and trajectory data) were processed using GrafNav GNSS post-processing software, using Precise Point Positioning (PPP) methods. Nearby Continuously Operating Reference Stations (CORS) were used as the vertical and horizontal control for this process. GNSS data were collected and processed in WGS84 (G1674) using the WGS84 ellipsoid.

Camera coordinates were converted to the North American Datum 1983 (NAD83, 2011) European Petroleum Survey Group Well Known Identification Number (EPSG) 6335 and the North American Vertical Datum of 1988 (NAVD88; Geoid12A; EPOCH 2010.00) using the National Geodetic Survey (NGS) VDatum tool (NOAA, 2018). The coordinates are projected in UTM Zone 6 North and are in meters.

The converted camera coordinates were manually correlated to image filenames to create a camera exterior orientation file for import into the photogrammetric software, Agisoft Photoscan Professional. The exterior orientation file provides the $\mathrm{X}, \mathrm{Y}$, and $\mathrm{Z}$ position for each photograph taken during the survey. Yaw, pitch, and roll information were not recorded during the flight.

The Trimble R7 Zephyr-2 base station position was corrected using the NGS Online Positioning User Service (OPUS) with the IGS08 (EPOCH 2015.6162). Checkpoint GNSS data were differentially corrected with the OPUS-corrected base station coordinates using GrafNet GNSS static network processing software. 


\section{PHOTOGRAMMETRY}

Aerial stereo-photographs were imported into the commercially available Agisoft Photoscan Professional software (Version 1.2.3 build 2331). Photos were processed in Photoscan on a Windows PC to align aerial photos, edit the sparse point cloud, optimize the bundle block adjustment, construct the dense point cloud and triangulated irregular network geometry, and export the natural color (RGB) orthoimagery GeoTIFF.

\section{DATA PRODUCTS}

Data files available for download are tiled DSM and natural color (RGB) orthoimagery GeoTIFFs. All data are projected in UTM Zone 6 North (meters) using the NAD83 (2011; EPSG 6335) horizontal datum and NAVD88 (Geoid12A; EPOCH 2010.00) vertical datum.

\section{DIGITAL SURFACE MODEL (DSM)}

DSMs represent surface elevations of all surfaces, including vegetation, vegetation-free land, bridges, buildings, etc. The Yukon River (not including tributaries and lakes within the study area) was hydro flattened using standardized hydro flattening workflow in ArcMap (McLean, 2018) with a resulting elevation change from $85.1 \mathrm{~m}$ in the east to $81.1 \mathrm{~m}$ in the west within the DSM boundary (east-west streamflow direction). The DSM is a single-band, 32-bit float GeoTIFF file, with a ground sample distance (GSD) of $0.47 \mathrm{~m}$. No Data value is set to $-3.40282306074 \mathrm{e}+038$.

\section{ORTHOIMAGERY}

The orthoimagery is a four-band, 16-bit unsigned GeoTIFF file. The orthoimagery has a GSD of $0.24 \mathrm{~m}$ per pixel, and the "No Data" value is set to 256 . Variable sky conditions during the photogrammetry survey resulted in some illumination anomalies in the southern part of the study area.

\section{DATA QUALITY}

The horizontal accuracy was assessed by comparing the locations of six GNSS-derived control points with their locations in the orthoimagery (fig. 2). The initial mean offset (residual) was $+1.35 \mathrm{~m}$ in the Xdirection and $-0.03 \mathrm{~m}$ in the Y-direction, with a standard deviation of $0.47 \mathrm{~m}(0.65 \mathrm{~m}$, Y-direction) and a mean-absolute-error (MAE) of $1.35 \mathrm{~m}$ (0.46 m, Y-direction) (table 1). A horizontal transformation of $1.35 \mathrm{~m}$ in X-direction was applied because horizontal offset was identified above the pixel scale of the DEM (i.e., $0.47 \mathrm{~m}$ GSD). The final horizontal accuracies were based on the same control points as checkpoints and are described in table 1.

The DSM was vertically controlled by comparing the elevation values of 9,794 points collected in transects along the highway on a paved surface in the photogrammetry-derived DSM to the elevation values at the same location in a lidar-derived dataset (bare earth DEM) collected in May 2011 (Hubbard and others, 2011). The initial mean vertical offset was $-1.60 \mathrm{~m}$ with a standard deviation of 0.38 and Root-MeanSquare-Error of $1.64 \mathrm{~m}$. A vertical transformation of $+1.60 \mathrm{~m}$ was applied. The final DSM vertical accuracy 
was evaluated with an additional 10,469 checkpoints and has a mean vertical residual of $0.02 \mathrm{~m}$ with a standard deviation of $0.41 \mathrm{~m}$ and an RMSE of $0.41 \mathrm{~m}$.

The DSM and orthoimagery have been visually inspected for data errors such as pits, border artifacts, and shifting. The end-user should be aware that pits and peaks are present in areas of some small water bodies, such as lakes and ponds, and that DSM data have not been hydro-flattened in these areas.

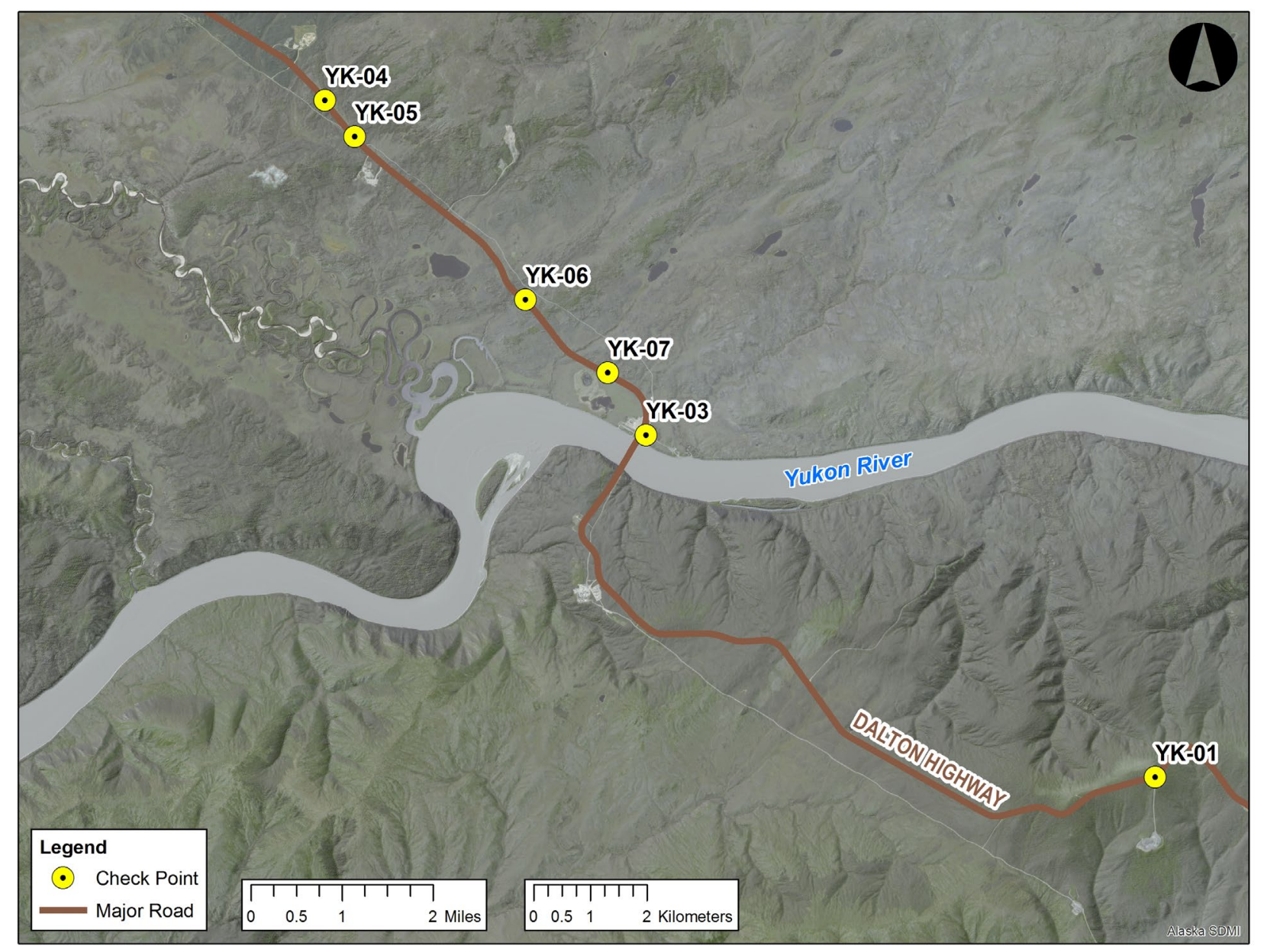

Figure 2. Location of GPS control points within the study area. 
Table 1. Horizontal accuracy assessment of the orthoimagery and DSM. All data are projected in UTM Zone 6 North (meters) using the NAD83 (2011; EPSG 6335) horizontal datum and NAVD88 (Geoid12A; EPOCH 2010.00) vertical datum.

\begin{tabular}{|c|c|c|c|c|c|}
\hline Check Point & Easting $(\mathrm{X})$ & Northing $(Y)$ & Elevation (m) & $\begin{array}{l}\text { Horizontal } \\
\text { Offset } X(m)\end{array}$ & $\begin{array}{l}\text { Horizontal } \\
\text { Offset } Y(m)\end{array}$ \\
\hline YK-01 & 385213.56 & 7303075.69 & 571.24 & 0.64 & -1.16 \\
\hline YK-03 & 376208.41 & 7309124.78 & 95.28 & 0.29 & 0.74 \\
\hline YK-04 & 370524.83 & 7315054.63 & 160.34 & -0.66 & 0.53 \\
\hline YK-05 & 371052.70 & 7314408.97 & 152.61 & 0.69 & -0.22 \\
\hline YK-06 & 374073.81 & 7311526.54 & 105.19 & -0.12 & -0.11 \\
\hline \multirow[t]{5}{*}{ YK-07 } & 375527.33 & 7310228.21 & 96.83 & 0.84 & 0.00 \\
\hline & & & Mean & 0.28 & -0.04 \\
\hline & & & Std. Dev & 0.58 & 0.67 \\
\hline & & & Range & 1.50 & 1.90 \\
\hline & & & MAE & 0.54 & 0.46 \\
\hline
\end{tabular}

\section{ACKNOWLEDGMENTS}

These data products were funded by the Alaska Department of Transportation \& Public Facilities, and Alaska Department of Natural Resources, Division of Geological \& Geophysical Surveys. We thank Clearwater Air for their aviation expertise and contribution to these data products.

\section{REFERENCES}

Hubbard, T.D., Koehler, R.D., and Combellick, R.A., 2011, High-resolution lidar data for Alaska infrastructure corridors: Alaska Division of Geological \& Geophysical Surveys Raw Data File 20113, 291 p. http://doi.org/10.14509/22722

McLean, K., 2018, Hydrological Flattening, accessed January 11, 2019.

http://katrinamclean.com/project/erdas-hydrologic-flattening-watershed-delineation-and-floodmodelling/

National Oceanic and Atmospheric Administration (NOAA), 2018, Online Vertical Datum Transformation. https://vdatum.noaa.gov/vdatumweb/ 